\title{
Effect of Carbon Emission and Human Errors on a Two-Echelon Supply Chain under Permissible Delay in Payments
}

\author{
Manavi Gilotra \\ Department of Mathematics \& Statistics, \\ Banasthali Vidyapith, Banasthali, 304022, India. \\ E-mail: manavi.gilotra@gmail.com \\ Sarla Pareek \\ Department of Mathematics \& Statistics, \\ Banasthali Vidyapith, Banasthali, 304022, India. \\ E-mail:psarla@banasthali.in \\ Mandeep Mittal \\ Department of Mathematics, \\ Amity Institute of Applied Sciences, Amity University, \\ Uttar Pradesh, Noida-201313, India. \\ Corresponding Author: mittal_mandeep@yahoo.com \\ Vinti Dhaka \\ Department of Mathematics, \\ Faculty of Physical Sciences, SGT University, Gurugram, 122006, India. \\ E-mail: dhakavinti@gmail.com
}

(Received May 15, 2019; Accepted October 8, 2019)

\begin{abstract}
Environmental worries in production and inventory models have received large attention in inventory management literature. In this paper, an economic production model is proposed with two-echelon supply chain when trade credit is offered by the supplier. This paper proposes human errors of Type I and Type II due to fatigue and inexperience of the inspector during screening. It considers the use of energy for production along with greenhouse gases (GHG) emission from production and transportation operations. The developed model optimizes the environmental and economic performances of the supply chain. Our aim is to explore the effects of human errors during inspection on the emission cost, transportation cost and delay in payment on the replenishment of order sizes and the expected total profit of the retailer. A mathematical model is developed and numerical examples are provided to illustrate the solution procedure.
\end{abstract}

Keywords- Supply chain, Trade credit, Emission cost, Fuel cost, Human errors.

\section{Introduction}

There is an increasingly common agreement that carbon footprints (carbon dioxide emissions and other greenhouse gas emissions), if ignored will lead to major changes in the climatic conditions of our environment system. Administrations are under growing pressure to enact regulation to restrict the emission of the harmful gages. In this direction, firms from all over the world are responding to such regulation and are undertaking initiatives to decrease their carbon footprint. However, these initiatives are more focused on reducing emissions due to the bodily processes involved. For example, replacement of unproductive equipment and facilities, reforming products and wrapping, finding sources of energy that are less polluting, or introducing energy savings 
International Journal of Mathematical, Engineering and Management Sciences

Vol. 5, No. 2, 225-236, 2020

https://doi.org/10.33889/IJMEMS.2020.5.2.018

programs. The attribute of quality and concern about the ecological surroundings with the perspective of inventory management have received considerable attention from researchers. Today, these topics are analyzed in an in depend manner.

Well known aim of a logistic network is to increase the financial act which was given by Beamon (1999). The expense due to carbon discharges is generally overlooked in finding choices. The significance of precisely estimating, announcing and lessening the carbon impression of a supply chain is expanding. For example, a hostile goal for dropping carbon emission has been set by Mexico, which aimed to reduce $50 \%$ of Greenhouse gases emissions by 2050 as compared to Güereca et al. (2013). In another precedent, an ongoing report by Blanco et al. (2016) found that a large number of the expansive firms in the United States revealed 22\% of their full extension 3 outflows in 2013.

The order, holding, and setup costs are the main segments of cost in supply chain. The ordering cost involves the cost of fuel as well as transportation among the other costs like salary of driver, a portion of vehicle's purchase cost, and vehicle maintenance cost among other costs which are elaborated in Waters (2003). Aggregation of these costs by the firms is for the easiness of computation and negotiation. In any case, these accumulations of expenses do not demonstrate the impact of a specific cost that could be expanding at a rate quicker than those of alternate expenses in the bundle. Transportation costs should also include fuel cost as its own component.

In general, it is assumed that each engineering system manufactures a product of good quality. Though, in a real situation, a certain quantity of items may be produced which are of imperfect quality. This can be due to the fault of machine or by ignorance of labour. Therefore, inspection turns out to be vital for all items that are produced before selling. However, several researchers overlooked the consequence of human errors (which can be because of fatigue, sickness and ignorance) during inspection process of the quality of the items in the supply chain models. Raouf et al. (1983) was the first one who proposed that mistakes can be made by inspector too. Zhang and Gerchak (1990) proposed an inspection policy for EOQ model where the yield considered is random quantity.

Shin et al. (2018) compared the two-echelon supply chain models. The first model was the effect of imperfect quality items while the second was effect of human errors. The effect of transportation and the emission through transportation was calculated. A model is proposed to find the effect of human error and emission through carbon on the supply chain.

Table 1. Contribution of different authors

\begin{tabular}{|l|c|c|c|c|}
\hline \multicolumn{1}{|c|}{ Author } & Trade credit & Carbon Emission & Imperfect quality & Human Error \\
\hline Salameh and Jaber (2000) & & & $\checkmark$ & \\
\hline Cárdenas-Barrón (2000) & & & $\checkmark$ & $\checkmark$ \\
\hline Duffuaa and Khan (2005) & & & $\checkmark$ & \\
\hline Maddah and Jaber (2008) & & & $\checkmark$ & \\
\hline Wee and Wu (2009) & & & & \\
\hline Khan et al. (2011) & & $\checkmark$ & $\checkmark$ & \\
\hline Hua et al. (2011) & & & & $\checkmark$ \\
\hline Jaggi et al. (2011) & $\checkmark$ & & & \\
\hline Khan et al. (2012) & & & & \\
\hline
\end{tabular}


International Journal of Mathematical, Engineering and Management Sciences

Vol. 5, No. 2, 225-236, 2020

https://doi.org/10.33889/IJMEMS.2020.5.2.018

Table 1 continued

\begin{tabular}{|l|c|c|c|c|}
\hline Kula and Gunalay (2012) & & $\checkmark$ & & \\
\hline Jaber et al. (2013) & & $\checkmark$ & $\checkmark$ & \\
\hline Jaggi et al. (2013) & & & & \\
\hline Khan et al. (2014) & & & & \\
\hline Gurtu et al. (2015) & & & & \\
\hline Bhunia et al. (2015) & & & & \\
\hline Tang et al. (2015) & & & & \\
\hline Sarkar (2016) & $\checkmark$ & $\checkmark$ & & \\
\hline Sarkar and Saren (2016) & & & & \\
\hline Zahran et al. (2016) & $\checkmark$ & & & \\
\hline Bazan et al. (2015) & $\checkmark$ & & & \\
\hline Aljazzar et al. (2016) & & & & \\
\hline Dhaka et al. (2017) & $\checkmark$ & & & \\
\hline Bouchery et al. (2017) & $\checkmark$ & & & \\
\hline Gilotra and Pareek (2018) & $\checkmark$ & & & \\
\hline Shin et al. (2018) & & & & \\
\hline Present Paper & & & & \\
\hline
\end{tabular}

Two-level supply chain model is proved with credit financing, carbon emission cost and human errors. In this model, the vendor manufactures only one product according to the buyer's demand. It is considered that goods produced or received are of imperfect quality, energy is consumed in the production system and the release of greenhouse gases from production and transportation operations. The model optimizes the economic and environmental performances of the network. The impact of imperfect quality items in the stock along with fuel cost, and emission cost from production and transportation is applied in different scenarios. Contributions of the various authors have been given in Table 1

\section{Assumption and Notation}

The following assumptions are considered to formulate the models.

\subsection{Assumption}

(i) A single type of item is delivered by a vendor to a buyer.

(ii) Human errors are considered in the inspection process. Two types of errors are considered.

(iii) Fixed time period is offered by the vendor to the buyer for settling the accounts. Interest is not charged during this period but will be charged after the completion of this period with certain terms and conditions.

(iv) Constant rate of demand and production is considered. Rate of production is greater than the rate of demand. (Wee et al., 2007).

(v) Items that are of perfect quality are considered as the imperfect item (Type I error) and imperfect item as perfect (Type II error) during inspection. (Shin et al., 2018).

(vi) All the trucks are of alike capacity, fuel consumption and emissions. No change in the consumption of fuel and emission over time and change in drivers. (Aljazzar et al., 2018).

(vii) Constant rate of emissions from the manufacturing process of product. 
International Journal of Mathematical, Engineering and Management Sciences

Vol. 5, No. 2, 225-236, 2020

https://doi.org/10.33889/IJMEMS.2020.5.2.018

\subsection{Notations}

The following notation are used to develop the model

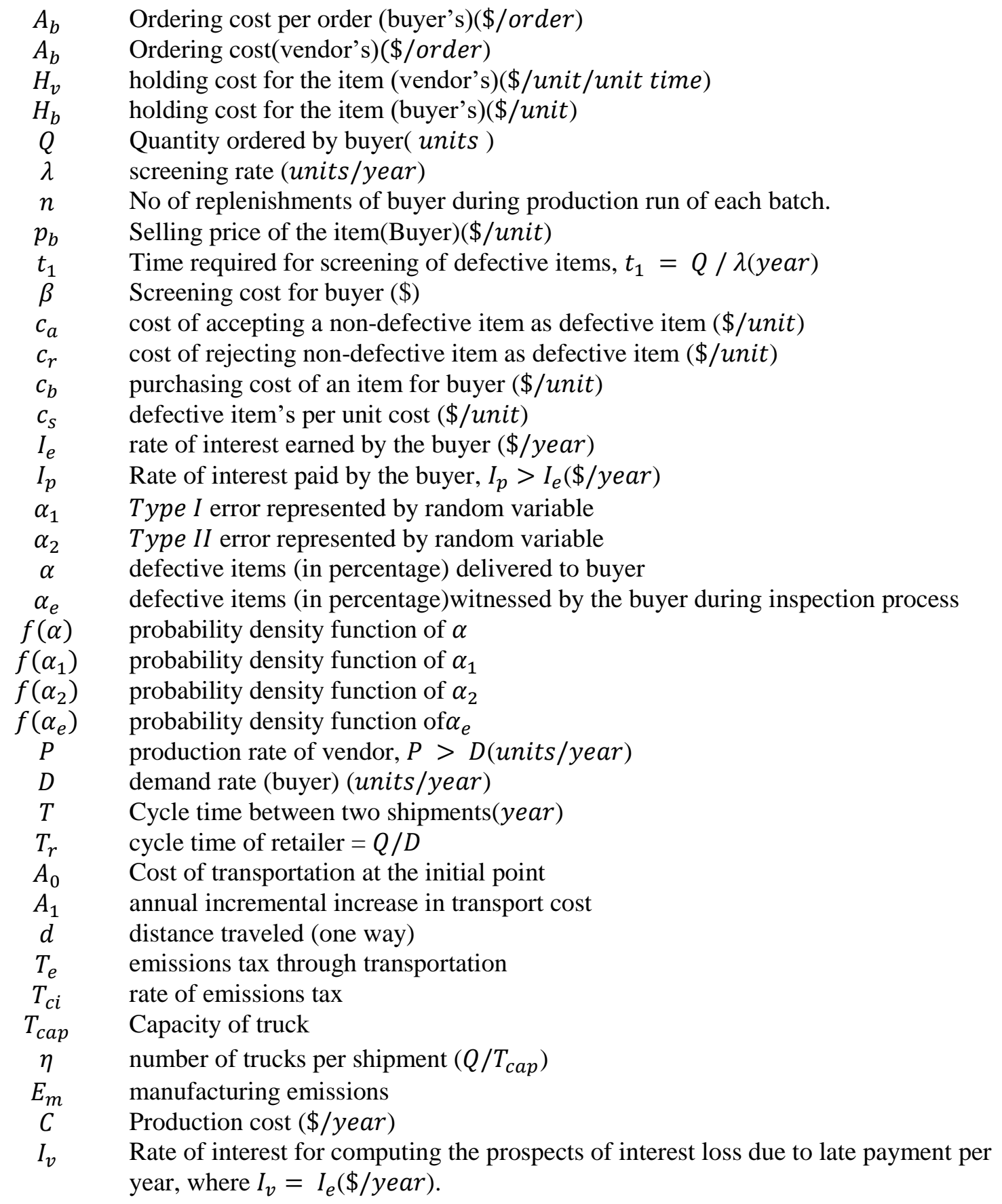

\section{Modelling}

According to Shin et al. (2018) as per Figure 1, every lot delivered contains $\alpha$ percentage of imperfect items with a known uniform probability density function, $f(\alpha)$. The lot delivered was inspected at a constant rate, $\lambda$ before selling it to the market. The rate of inspection is presumed to 
International Journal of Mathematical, Engineering and Management Sciences

Vol. 5, No. 2, 225-236, 2020

https://doi.org/10.33889/IJMEMS.2020.5.2.018

be greater than the rate of demand, $\lambda>D$ for avoiding the shortages. However, during the inspection process, inspector by mistake selects perfect item as imperfect (defective) (Type I error) and imperfect item as defective (Type II error). A total expected cost including cost of credit financing, carbon emission cost and human errors in the supply chain is obtained.

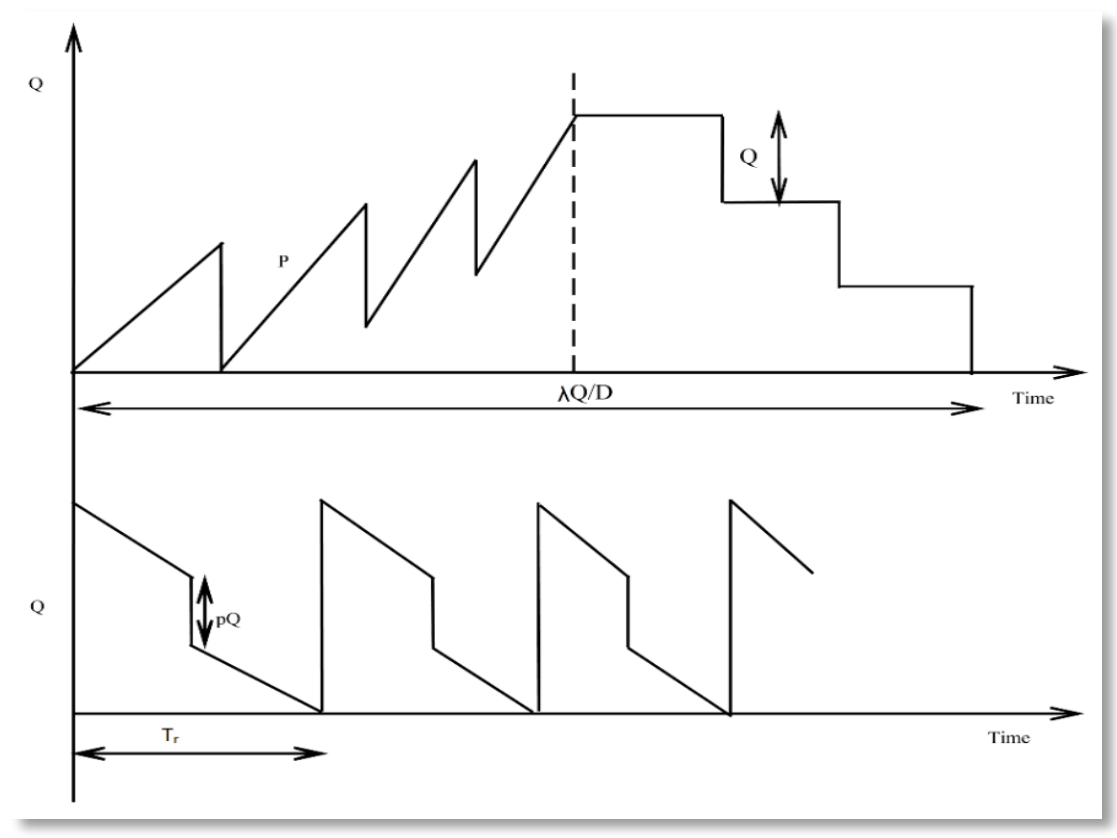

Figure 1. The basic model for vendor and buyer

The lot is inspected with constant rate. $\alpha_{1}$ items are incorrectly categorized as imperfect from the $(1-\alpha) \alpha_{1}$ perfect items, and $\alpha_{2}$ items are incorrectly acknowledged as perfect items from the $\alpha\left(1-\alpha_{2}\right)$ imperfect items. The imperfect items as detected by the inspector are $\alpha_{e}$ and equal to $(1-\alpha) \alpha_{1}+\alpha\left(1-\alpha_{2}\right) . \alpha, \alpha_{1}, \alpha_{2}$ and $\alpha_{e}$ are assumed random variables. Thus, the total expected value of imperfect items is $E\left[\alpha_{e}\right]$ can be written as $(1-E[\alpha]) E\left[\alpha_{1}\right]+$ $E[\alpha]\left(1-E\left[\alpha_{2}\right]\right)$. The expected time $E[T]$ between two shipments is equal to $\left(1-E\left[\alpha_{e}\right]\right) Q$ / $D$.The total expected cost of the vendor bearing in mind the total defective items observed is given by

$E\left[T C_{v}(n, Q)\right]=A_{v}+\frac{H_{v} n Q^{2}}{2 D}\left\{(n-1)-(n-2) \frac{D}{P}\right\}+\frac{c n Q}{P}+I_{v} c_{b} n\left(1-E\left[\alpha_{e}\right]\right) Q M+E_{m} Y T_{c i}$

For the expected total cost of buyer, cost of order, cost of holding the quantity, emission through transportation \& screening cost are measured with total imperfect items $\alpha_{e}$ claimed by the inspector. These misclassification costs have two constitute that are included in the total cost of buyer,

(i) Expected cost associated with accepting defective items which were non-defective is $c_{a} E[\alpha] n Q E\left[\alpha_{2}\right]$. 
International Journal of Mathematical, Engineering and Management Sciences

Vol. 5, No. 2, 225-236, 2020

https://doi.org/10.33889/IJMEMS.2020.5.2.018

(ii) Expected cost associated with rejecting non-defective items which were defective is $c_{r}\left(1-E[\alpha] n Q E\left[\alpha_{1}\right]\right)$.

Shortages are avoided by considering that screened lot is higher than or equal to the demand through inspection $t_{1}=(Q / \lambda)$ i.e.,

$\left(1-E\left[\alpha_{e}\right]\right) Q \geq D t_{1} \Rightarrow E\left[\alpha_{e}\right] \leq 1-D / \lambda$.

$M$ is the fixed period offered by vendor to buyer to settle the account. There will be three different possible cases for the calculation of buyer's cost, $T C_{b j}(n, Q), j=1,2,3$

Case 1: $M \leq t_{1} \leq T$

Case 2: $t_{1} \leq M \leq T$

Case 3: $M \geq T$.

Case 1: $M \leq t_{1} \leq T$

The interest earned by buyer during time period 0 to $M$ is $p_{b} I_{e} D M^{2} / 2$ and the interest paid for the inventory not sold after the credit period, $M$, is $c_{b} I_{p} D(T-M)^{2} / 2+c_{s} I_{p} \alpha_{e} n Q\left(t_{1}-M\right)$. The total cost of the buyer $T C_{b 1}(n, Q)$ is summation of all the cost components. The total expected cost $E\left[T C_{b 1}(n, Q)\right]$ is

$$
\begin{aligned}
& E\left[T C_{b 1}(n, Q)\right]=\frac{\eta T_{e} D}{Q}+\frac{\eta D A_{0}}{Q}+\frac{1}{2} \eta A_{1}(2 k n-n-1)+c_{r}(1-E[\alpha]) n Q E\left[\alpha_{1}\right]+ \\
& c_{a} E[\alpha] n Q E\left[\alpha_{2}\right]+c_{s} I_{p} E\left[\alpha_{e}\right] n Q\left(\frac{Q}{\lambda}-M\right)+\frac{c_{b} I_{p} D}{2}\left\{\frac{E\left[\left(1-\alpha_{e}\right)^{2}\right] Q^{2}}{D}+M^{2}-\frac{2\left(1-E\left[\alpha_{e}\right]\right) Q M}{D}\right\}- \\
& \frac{p_{b} I_{e} D M^{2}}{2}+\beta(n Q \beta)+n H_{b}\left\{\frac{E\left[\left(1-\alpha_{e}\right)^{2}\right] Q^{2}}{2 D}+\frac{E\left[\alpha_{e}\right] Q^{2}}{\lambda}\right\}+A_{b}
\end{aligned}
$$

The total expected cost of buyer per unit time is

$$
E\left[T C_{b 1}^{T}(n, Q)\right]=E\left[T C_{b 1}(n, Q)\right] / n E[T]
$$

\section{Case 2: $t_{1} \leq M \leq T$}

The expected cost of buyer $E\left[T C_{b 2}(n, Q)\right]$ is

$$
\begin{aligned}
& E\left[T C_{b 2}(n, Q)\right]=\frac{\eta T_{e} D}{Q}+\frac{\eta D A_{0}}{Q}+\frac{1}{2} \eta A_{1}(2 k n-n-1)+c_{r}(1-E[\alpha]) n Q E\left[\alpha_{1}\right]+ \\
& c_{a} E[\alpha] n Q E\left[\alpha_{2}\right]-c_{s} I_{p} E\left[\alpha_{e}\right] n Q\left(M-\frac{Q}{\lambda}\right)+\frac{c_{b} I_{p} D}{2}\left\{\frac{E\left[\left(1-\alpha_{e}\right)^{2}\right] Q^{2}}{D}+M^{2}-\frac{2\left(1-E\left[\alpha_{e}\right]\right) Q M}{D}\right\}- \\
& \frac{p_{b} I_{e} D M^{2}}{2}+\beta(n Q \beta)+n H_{b}\left\{\frac{E\left[\left(1-\alpha_{e}\right)^{2}\right] Q^{2}}{2 D}+\frac{E\left[\alpha_{e}\right] Q^{2}}{\lambda}\right\}+A_{b}
\end{aligned}
$$

The total expected cost of buyer per unit time is

$E\left[T C_{b 2}^{T}(n, Q)\right]=E\left[T C_{b 2}(n, Q)\right] / n E[T]$

Case 3: $M \geq T$

The expected cost of buyer $E\left[T C_{b 3}(n, Q)\right]$ is 
International Journal of Mathematical, Engineering and Management Sciences

Vol. 5, No. 2, 225-236, 2020

https://doi.org/10.33889/IJMEMS.2020.5.2.018

$$
\begin{aligned}
& E\left[T C_{b 3}(n, Q)\right]=\frac{\eta T_{e} D}{Q}+\frac{\eta D A_{0}}{Q}+\frac{1}{2} \eta A_{1}(2 k n-n-1)+c_{r}(1-E[\alpha]) n Q E\left[\alpha_{1}\right]+ \\
& c_{a} E[\alpha] n Q E\left[\alpha_{2}\right]-c_{s} I_{p} E\left[\alpha_{e}\right] n Q\left(M-\frac{Q}{\lambda}\right)-\frac{p_{b} I_{e} D}{2}\left\{\frac{\left(1-E\left[\alpha_{e}\right]\right) Q M}{D}-\frac{E\left[\left(1-\alpha_{e}\right)^{2}\right] Q^{2}}{D^{2}}\right\}- \\
& \frac{p_{b} I_{e} D E\left[\left(1-\alpha_{e}\right)^{2}\right] Q^{2}}{2 D^{2}}+\beta(n Q \beta)+n H_{b}\left\{\frac{E\left[\left(1-\alpha_{e}\right)^{2}\right] Q^{2}}{2 D}+\frac{E\left[\alpha_{e}\right] Q^{2}}{\lambda}\right\}+A_{b}
\end{aligned}
$$

The total expected cost of buyer per unit time is

$$
E\left[T C_{b 3}^{T}(n, Q)\right]=E\left[T C_{b 3}(n, Q)\right] / n E[T]
$$

From equation (1), total expected cost of vendor for all 3 cases can be stated as

$$
E\left[T C_{v j}(n, Q)\right]=E\left[T C_{v j}(n, Q)\right], \quad j=1,2,3
$$

Total expected cost for all the three cases is expressed as

$$
E\left[\operatorname{TCS}_{j}(n, Q)\right]=E\left[T C_{v j}(n, Q)\right]+E\left[T C_{b j}(n, Q)\right], \quad j=1,2,3
$$

$\mathrm{E}\left[\operatorname{TCS}_{j}^{T}(n, Q)\right], j=1,2,3$ for all three cases are determined as given below

$$
\mathrm{E}\left[\operatorname{TCS}_{j}^{T}(n, Q)\right]=E\left[\operatorname{TCS}_{j}(n, Q) / n T\right]=E\left[\operatorname{TCS}_{j}(n, Q)\right] / n E[T], j=1,2,3
$$

By differentiating equation with respect to $Q$ and equating it to zero we get the optimal order quantity $Q^{*}$,

$$
\frac{\partial E\left[\operatorname{TCS}_{1}^{T}(n, Q)\right]}{\partial Q}=0
$$

Sufficient condition has to be satisfied so that the total expected cost of the supply chain to be convex,

$$
\frac{\partial^{2} E\left[T C S_{1}^{T}(n, Q)\right]}{\partial Q^{2}}>0
$$

To obtain the optimal order quantity in all the three cases DMS Algorithm 2 Shin et al. (2018) is applied.

\section{Numerical Example}

Following is example is shown for the effect of human error Shin et al. (2018) and carbon emission on supply chain.

$D=1000$ unit/year $, P=3,200$ unit/year $, c=100,000 \$ /$ year, $A_{v}=$ $400 \$ /$ cycle, $A_{b}=25 \$ /$ cycle,,$H_{b}=5 \$$ /unit, $H_{v}=4 \$ /$ unit,$v=2 \$ /$ unit,$\lambda=$ $175,200 \frac{\text { unit }}{\text { year }}, \beta=0.5 \frac{\$}{\text { unit }}, c_{a}=200 \frac{\$}{\text { unit }}, c_{r}=50 \frac{\$}{\text { unit }}$ and $\alpha$ is assume to be uniformly distributed with its probability density function, $f(\alpha)=\left\{\begin{array}{cc}\frac{1}{0.04-0}, & 0 \leq \alpha \leq 0.04 \\ 0, & \text { otherwise }\end{array}\right.$. Human errors are assumed and the random variables for Type I and Type II errors are presumed to be distributed uniformly, their probability density functions are given as, $f\left(\alpha_{1}\right)=$ 
$\left\{\begin{array}{cc}\frac{1}{0.04-0}, & 0 \leq \alpha \leq 0.04 \\ 0, & \text { otherwise }\end{array}, f\left(\alpha_{2}\right)=\left\{\begin{array}{cc}\frac{1}{0.04-0}, & 0 \leq \alpha \leq 0.04 \\ 0, & \text { otherwise }\end{array}\right.\right.$ and the expected value of the parameters are, $E[\alpha]=0.02, E\left[\alpha_{1}\right]=0.02, E\left[\alpha_{2}\right]=0.02$, expected value of the observed total defective items, $E\left[\alpha_{e}\right]=(1-E[\alpha]) E\left[\alpha_{1}\right]+E[\alpha]\left(1-E\left[\alpha_{2}\right]\right)$ is $E\left[\alpha_{e}\right]=0.0392$, the value of $E\left[\left(1-\alpha_{e}\right)^{2}\right]=0.925, c_{b}=30 \$ /$ unit,$p_{b}=120 \$ /$ unit,$c_{s}=60 \$ /$ unit,$I_{e}=$ $0.04 \$ /$ year,$I_{p}=0.08 \$ /$ year,$I_{v}=0.04 \$ /$ year, and $M=0.33$ year. We check the condition on $E\left[\alpha_{e}\right]$ given by the equation, $E\left[\alpha_{e}\right] \leq 1-D / \lambda$ for the values mentioned above for avoiding the shortages during inspection process, i.e., $E\left[\alpha_{e}\right] \leq 0.9943$. For the case when $M=0$, the results are given as: $n^{*}=4, Q^{*}=122$ units, and $E[T]=0.23$ year and the total expected cost of supply chain, $\operatorname{E}[\operatorname{TCST}(n, Q)]=\$ 40,500$.

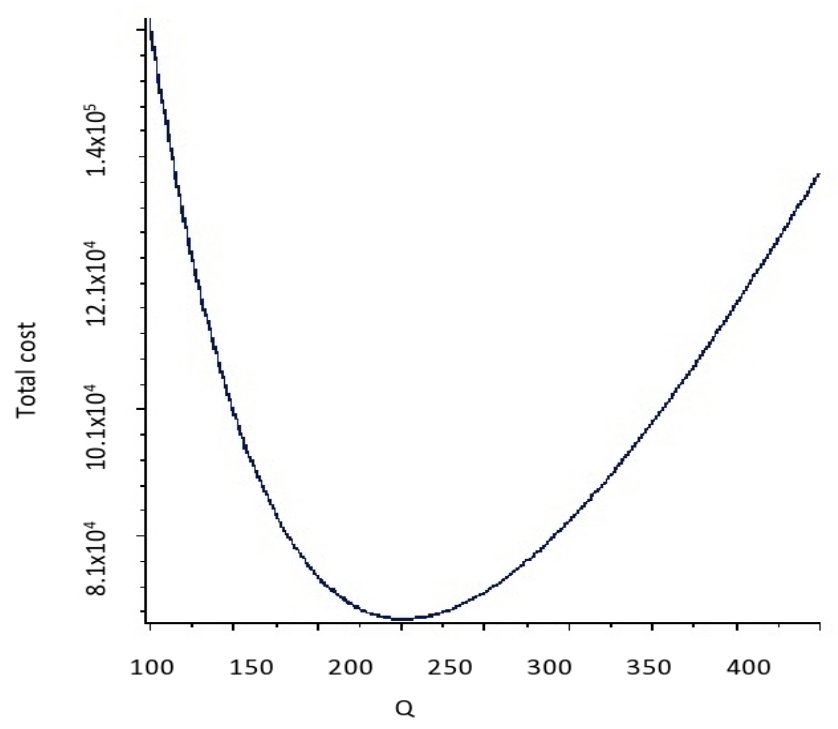

Figure 2. Convexity of the total cost vs order quantity for best case 2

The Figure 2 shows that Case $2\left(\boldsymbol{t}_{\mathbf{1}} \leq \boldsymbol{M} \leq \boldsymbol{T}\right)$ is the optimal solution when $n^{*}=2, Q^{*}=235$ units, $E[T]=0.41$ year and the total expected cost of supply chain, $E[\operatorname{TCST}(n, Q)]=$ $\$ 67,173$.

\subsection{Sensitivity Analysis}

Sensitivity analysis is made on different factors to find the effect of Type I and Type II error, effect of rate of change of errors and the carbon emission because of transportation on the total expected cost. 
International Journal of Mathematical, Engineering and Management Sciences

Vol. 5, No. 2, 225-236, 2020

https://doi.org/10.33889/IJMEMS.2020.5.2.018

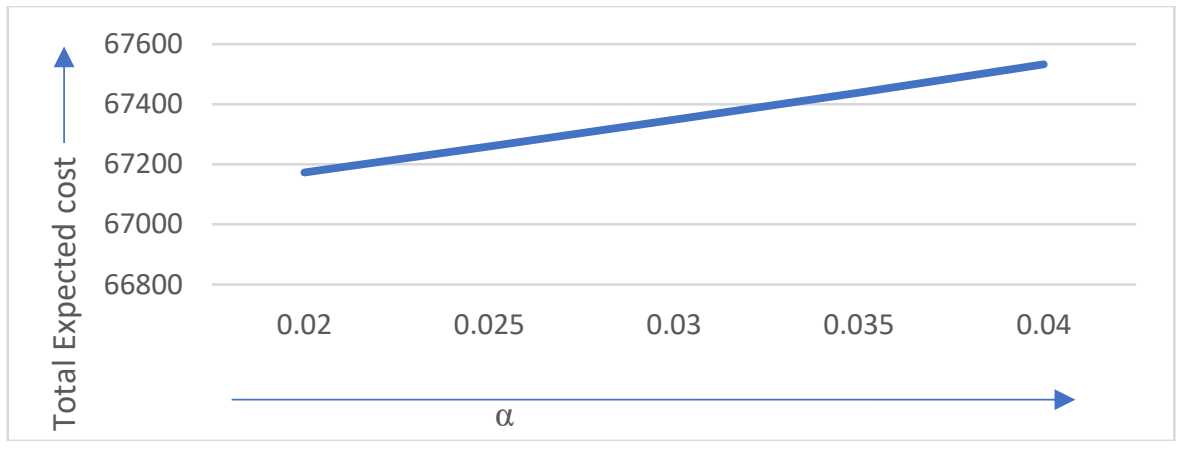

Figure 3. Effect of rate of change of human error on total cost

Here graph clearly proves that growth in the errors (Type I and Type II error)is directly proportional to the cost for the whole supply chain.

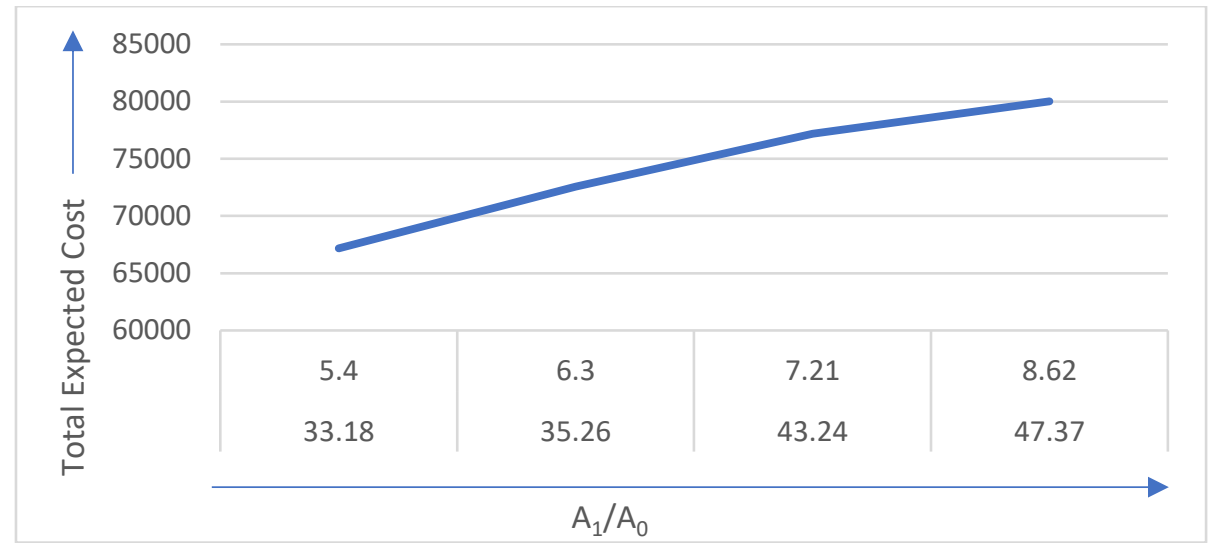

Figure 4. Effect of rate of change of carbon emission on total cost

The increment of emission from the whole supply chain (including transportation and emission rate) will increase the total cost. The increment in carbon emission will also affect the environment causing more pollution.

From Figure 3 it can be concluded that the variation in the inspection process due to inspector mistakes affect the final cost of the supply chain. More the variation because of tiredness or ill health will lead to higher investment from the buyer.

Figure 4 represents the effect of emission of carbon from transportation and production on the supply chain. The carbon emission tax will increase with the emission. Definitely it will increase the total cost of supply chain. The increment in carbon emission affects the supply chain but also the environment dangerously. 
International Journal of Mathematical, Engineering and Management Sciences

Vol. 5, No. 2, 225-236, 2020

https://doi.org/10.33889/IJMEMS.2020.5.2.018

\section{Managerial Insights}

Some practical applications exist for this paper. The carbon emission from transportation and the production process will not only affect the environment but also upsurge the cost of the model. Human error will lead to addition of another cost in the supply chain. The delay in payment process helps in reduction of cost in supply chain but the addition of emission cost and human error cost increases the total cost.

The effect of different parameters on the total cost has been represented in the figures. The presence of defective items in the lot and emission from the transport increases the cost and the pollution in the environment. We should work on the remedies to reduce pollution like by planting of more trees and maintaining the vehicles.

\section{Conclusion}

In this paper, an inventory model is formulated considering the effect of human errors on the supply chain when carbon emission tax is taken into consideration. The effect of presence of human errors and carbon emission can be seen from the graph. As number of imperfect quality items increase the final cost of the vendor and the buyer both increases. The presence of imperfect quality items lead to more demand from the retailer which will indirectly lead to more carbon emission. It will also lead to more demand from the vendor which will ultimately require more production and transportation. Extra transportation means more carbon emission which is harmful to the environment. Therefore, perfect cautions should be taken while handling the lot, during inspection process. For future research rework as well as salvage value can be added for imperfect items.

\section{Conflict of Interest}

The authors confirm that there is no conflict of interest to declare for this publication.

\section{Acknowledgement}

The authors would like to thank the reviewers for their positive and helpful comments.

\section{References}

Aljazzar, S.M., Gurtu, A., \& Jaber, M.Y. (2018). Delay-in-payments-A strategy to reduce carbon emissions from supply chains. Journal of Cleaner Production, 170, 636-644.

Aljazzar, S.M., Jaber, M.Y., \& Goyal, S.K. (2016). Coordination of a two-level supply chain (manufacturer-retailer) with permissible delay in payments. International Journal of Systems Science: Operations \& Logistics, 3(3), 176-188.

Bazan, E., Jaber, M.Y., \& Zanoni, S. (2015). Supply chain models with greenhouse gases emissions, energy usage and different coordination decisions. Applied Mathematical Modelling, 39(17), 51315151.

Beamon, B.M. (1999). Measuring supply chain performance. International Journal of Operations \&Production Management, 19(3), 275-292.

Blanco, C., Caro, F., \& Corbett, C.J. (2016). The state of supply chain carbon footprinting: analysis of CDP disclosures by US firms. Journal of Cleaner Production, 135, 1189-1197. 
International Journal of Mathematical, Engineering and Management Sciences

Vol. 5, No. 2, 225-236, 2020

https://doi.org/10.33889/IJMEMS.2020.5.2.018

Bouchery, Y., Ghaffari, A., Jemai, Z., \& Tan, T. (2017). Impact of coordination on costs and carbon emissions for a two-echelon serial economic order quantity problem. European Journal of Operational Research, 260(2), 520-533.

Bhunia, A., Shaikh, A., Pareek, S., \& Dhaka, V. (2015). A memo on stock model with partial backlogging under delay in payments. Uncertain Supply Chain Management, 3(1), 11-20.

Cárdenas-Barrón, L.E. (2000). Observation on:"Economic production quantity model for items with imperfect quality" [Int. J. Production Economics 64 (2000) 59-64]. International Journal of Production Economics, 67(2), 201-201.

Dhaka, V., Pareek, S., \& Jaggi, C.K. (2017). Inventory model for optimal pricing and ordering policies under two-level trade credits. International Journal of Procurement Management, 10(5), 555-567.

Duffuaa, S.O., \& Khan, M. (2005). Impact of inspection errors on the performance measures of a general repeat inspection plan. International Journal of Production Research, 43(23), 4945-4967.

Gilotra, M., \& Pareek, S. (2018). Two-level trade credit in supply chain management quadratic with fix life under quadratic demand. In Handbook of Research on Promoting Business Process Improvement Through Inventory Control Techniques (pp. 141-155). IGI Global.

Güereca, L.P., Torres, N., \& Noyola, A. (2013). Carbon Footprint as a basis for a cleaner research institute in Mexico. Journal of Cleaner Production, 47, 396-403.

Gurtu, A., Jaber, M.Y., \& Searcy, C. (2015). Impact of fuel price and emissions on inventory policies. Applied Mathematical Modelling, 39(3-4), 1202-1216.

Hua, G., Cheng, T.C.E., \& Wang, S. (2011). Managing carbon footprints in inventory management. International Journal of Production Economics, 132(2), 178-185.

Jaggi, C.K., Goel, S.K., \& Mittal, M. (2011). Economic order quantity model for deteriorating items with imperfect quality and permissible delay on payment. International Journal of Industrial Engineering Computations, 2(2), 237-248.

Jaggi, C.K., Goel, S.K., \& Mittal, M. (2013). Credit financing in economic ordering policies for defective items with allowable shortages. Applied Mathematics and Computation, 219(10), 5268-5282.

Jaber, M.Y., Glock, C.H., \& El Saadany, A.M. (2013). Supply chain coordination with emissions reduction incentives. International Journal of Production Research, 51(1), 69-82.

Khan, M., Jaber, M.Y., \& Bonney, M. (2011). An economic order quantity (EOQ) for items with imperfect quality and inspection errors. International Journal of Production Economics, 133(1), 113-118.

Khan, M., Jaber, M.Y., \& Guiffrida, A.L. (2012). The effect of human factors on the performance of a two level supply chain. International Journal of Production Research, 50(2), 517-533.

Khan, M., Jaber, M.Y., \& Ahmad, A.R. (2014). An integrated supply chain model with errors in quality inspection and learning in production. Omega, 42(1), 16-24.

Kula, E., \& Gunalay, Y. (2012). Carbon sequestration, optimum forest rotation and their environmental impact. Environmental Impact Assessment Review, 37, 18-22.

Maddah, B., \& Jaber, M.Y. (2008). Economic order quantity for items with imperfect quality: revisited. International Journal of Production Economics, 112(2), 808-815.

Raouf, A., Jain, J.K., \& Sathe, P.T. (1983). A cost-minimization model for multicharacteristic component inspection. AIIE Transactions, 15(3), 187-194.

Salameh, M.K., \& Jaber, M.Y. (2000). Economic production quantity model for items with imperfect quality. International Journal of Production Economics, 64(1-3), 59-64. 
International Journal of Mathematical, Engineering and Management Sciences

Vol. 5, No. 2, 225-236, 2020

https://doi.org/10.33889/IJMEMS.2020.5.2.018

Sarkar, B. (2016). Supply chain coordination with variable backorder, inspections, and discount policy for fixed lifetime products. Mathematical Problems in Engineering, 2016.

Sarkar, B., \& Saren, S. (2016). Product inspection policy for an imperfect production system with inspection errors and warranty cost. European Journal of Operational Research, 248(1), 263-271.

Shin, D., Mittal, M., \& Sarkar, B. (2018). Effects of human errors and trade-credit financing in two-echelon supply chain models. European Journal of Industrial Engineering, 12(4), 465-503.

Tang, S., Wang, W., Yan, H., \& Hao, G. (2015). Low carbon logistics: Reducing shipment frequency to cut carbon emissions. International Journal of Production Economics, 164, 339-350.

Waters, D. (2003). Inventory control and management. John Wiley \& Sons

Wee, H.M., \& Wu, S. (2009). Lean supply chain and its effect on product cost and quality: a case study on Ford Motor Company. Supply Chain Management: An International Journal, 14(5), 335-341.

Wee, H.M., Yu, J., \& Chen, M.C. (2007). Optimal inventory model for items with imperfect quality and shortage backordering. Omega, 35(1), 7-11.

Zhang, X.I.N., \& Gerchak, Y.I.G.A.L. (1990). Joint lot sizing and inspection policy in an EOQ model with random yield. IIE Transactions, 22(1), 41-47.

Zahran, S.K., Jaber, M.Y., \& Zanoni, S. (2016). The consignment stock case for a vendor and a buyer with delay-in-payments. Computers \& Industrial Engineering, 98, 333-349. 